\title{
A descriptive survey of online gaming characteristics and gaming disorder in Ireland
}

\author{
David Columb ${ }^{1 *}$ (1), Mark D Griffiths ${ }^{2}$ and Colin $\mathrm{O}^{\prime} \mathrm{Gara}^{1 / 3}$ \\ ${ }^{1}$ Addiction Department, St John of God Hospital, Stillorgan, Co Dublin, Ireland \\ ${ }^{2}$ Behavioural Addiction, Nottingham Trent University, Nottingham, UK \\ ${ }^{3}$ School of Medicine and Medical Specialties, University College Dublin, Dublin, Ireland
}

\begin{abstract}
Objectives

The aim of this study was to carry out the first ever study of gaming characteristics of individuals engaging in online gaming in Ireland and to ascertain whether features of gaming disorder are present in this population.
\end{abstract}

\section{Methods}

An online survey (comprising 21 questions - three demographic questions and 18 questions related to gaming and gaming disorder) was distributed on numerous Irish online gaming forums and Irish online gaming communities. Participants were self-selecting and invited to compete the online survey containing questions related to gaming behaviours (age of onset, hours played on weekdays/weekends, type of device used), mobile gaming, motives for online gaming, use of microtransactions, engagement in esports and a screening tool for the presence of gaming disorder.

\section{Results}

A total of 166 participants engaged in the online survey. Among this study population of regular gamers in Ireland, $2.4 \%$ of the study population were classified as having gaming disorder, with up to $5.4 \%$ showing some evidence of disordered gaming. The main motivation for online gaming in the non-disordered gaming group was recreation $(13.3$, S.D. $=2.7)$ but only the fourth main motivation in the disordered gaming group behind competition (16.3, S.D. =3.7), escape $(16.2$, S.D. $=4.3)$, and coping $(15.1$, S.D. = 3.7). Increased hours of gameplay on weekdays and weekends were noted in the disordered gaming group compared to nondisordered gamers.

\section{Conclusions}

A small percentage of gamers in Ireland demonstrate disordered gaming characteristics and gaming disorder, consistent with data from other international studies. Epidemiological studies are required in Ireland to enhance our knowledge of this disorder.

\section{Keywords}

Gaming disorder, gaming addiction, online gaming, behavioural addiction, mobile gaming, esports, microtransactions, Ireland. 


\section{Introduction}

The playing of videogames is a rapidly growing leisure activity worldwide. Since the advent of the Massively Multiplayer Online Role-Playing Games (MMORPGs) in the early 2000s, games like World of Warcraft have allowed players to engage online with one another via online gaming platforms (GamesIndustry International, 2004). More recently, the gaming landscape has been dominated by newer gaming platforms such as Multiplayer Online Battle Arena (MOBA) games and Online Multiplayer Battle Royale games (WePC, 2019). MOBA games (e.g. League of Legends) consist of players forming teams to complete against each other in combat situations (Meng et al., 2015). Online Multiplayer Battle Royale games (e.g. PlayerUnknown's Battlegrounds [PUBG], Fortnite) pit individuals or teams against each other in a 'last-man-standing' combat format (Mamun and Griffiths, 2019). These games are immensely popular, with Fortnite reaching a peak of 3.4 million players worldwide concurrently online in August 2018 (Chalk, 2018). In Ireland, a recent survey conducted by a telecommunication company reported that $36 \%$ of the Irish adult population currently engage in online gaming (O'Brien, 2019).

The structural characteristics of these genres make them ideal candidates for use in esports. Esports are 'competitive (pro and amateur) video gaming that is often coordinated by different leagues, ladders, and tournaments, and where players customarily belong to teams or other 'sporting' organizations who are sponsored by various business organizations' (Hamari and Sjöblom, 2017, p. 211). Esports have garnered significant Irish media interest in recent years, from Ireland hosting its first esports event in May 2018 (Cocking, 2018) to an Irish teenager winning \$50,000 for his high finishing position in the Fortnite World Cup (Pollak and Gallagher, 2019). With these new popular platforms for online gaming, there has been an increase in gaming revenue. The videogame market in 2017 generated over $\$ 78$ billion (US) (WePC , 2019) and this figure is predicted to rise to as much as $\$ 300$ billion (US) by the year 2025 (Lanier, 2019).

With the increased popularity and usage of gaming, there is an increased risk of the development of gaming disorder among a minority of individuals (Mihara and Higuchi, 2017). Gaming disorder was recently introduced into the International Classification of Diseases and Related Health Problems (ICD-11) under 'Disorders due to substance misuse or addictive behaviours' (World Health Organization, 2018). Gaming disorder is classified as persistent or recurrent online or offline gaming behaviours that display impaired control over gaming, increased priority given to gaming over other pursuits, and continuation of gaming despite harmful consequences (World Health Organization, 2018). It is important to state that, for the majority of individuals, gaming and online gaming is a pleasurable, recreational pursuit that can have positive social and emotional benefits (Columb et al., 2019). However, for the individuals affected by gaming disorder, it can have personal, social, and emotional consequences (Columb et al., 2019).

Gaming disorder has an estimated prevalence worldwide of up to 4.7\% (Feng et al., 2017) with higher prevalence in males compared to females (Mihara and Higuchi, 2017). In Ireland, there are no data available on the prevalence of gaming disorder or the characteristics and behaviours of individuals engaging in playing videogames. In addition, there are very few treatment facilities available for gaming disorder in Ireland. This raises concerns because young patients are already presenting to psychiatrists in Ireland seeking treatment for gaming disorder as stated in an interview with Dr Gerry McCarney, a consultant Child and Adolescent Psychiatrist working in Ireland (Kelleher, 2019). Given the lack of data in Ireland in relation to gaming and gaming disorder, the aim of this study was to examine the gaming characteristics of individuals 
engaging in online gaming in Ireland and to ascertain whether features of gaming disorder are present in this population.

\section{Methods}

\section{Participants}

Between November 2018 and April 2019, 166 participants engaged in an online survey focusing on gaming characteristics and gaming addiction. The survey questionnaire was posted on numerous Irish online gaming forums (Boards.ie Gaming [General] forum, League of Legends Ireland forum, and PC Gaming Ireland forum), as well as an Irish online gaming community (Irish Gamers Community). A short explanation of the study was posted along with a link to the survey. An information sheet detailing the outline of the study, the reasons behind the study, how the participant's data would be used, the risks and benefits of the study as well as the relevant General Data Protection Regulation (GDPR) information was provided at the beginning of the survey. A consent form followed this information sheet confirming their understanding of the information sheet, their voluntary agreement to participate in the study, their understanding of how their data would be used, and their opportunity to ask questions prior to completing the questionnaire. Ethical approval was obtained from the Human Research Ethics Committee of University College Dublin.

\section{Survey design}

The survey comprised 21 questions with three demographic questions and 18 questions related to gaming and gaming disorder. Demographic questions consisted of age, gender, and nationality. Gaming questions enquired about age of onset of gaming and the hours spent gaming (on weekends and weekdays). Participants were asked to select the games they regularly played from a list of 27 popular online games. The type of device used for gaming (console gaming, mobile gaming, personal computer [PC] gaming) and frequency of use of these devices were enquired about on an eight-point Likert scale ("I do not use this type of device" to "every day").

Mobile gaming questions were included in the survey including age of onset of mobile gaming and the hours spent mobile gaming (on weekends and weekdays). The frequency of play of the most popular mobile games were assessed using an eight-point Likert scale (no play to every day). The mobile games assessed were Candy Crush Saga, Fortnite, Pokemon Go!, Toon Blast, Candy Crush Soda Saga, Clash of Clans, ROBLOX, Guns of Glory, Dragon Ball Z and Dokkan Battle, based on the most popular games available on mobile devices.

The survey included two psychometric scales related to gaming and gaming disorder - the nine-item Internet Gaming Disorder Scale - Short Form (IGDS9-SF) and the Motives for Online Gaming Questionnaire (MOGQ). The IGDS9-SF is a brief, reliable and valid scale (Pontes and Griffiths, 2015) comprising nine questions responded to on a five-point Likert scale from 1 ("never") to 5 ("very often") based on the criteria for Internet Gaming Disorder outlined in the Diagnostic and Statistical Manual of Mental Disorders (DSM-5; American Psychiatric Association, 2013). Scores can range from 9 to 45. Endorsing five or more items out of nine in the most severe range (i.e., 5) indicates gaming disorder. The Motives for Online Gaming Questionnaire is a 27-item scale assessing seven main motives for online gaming (social, escape, competition, coping, skill development, fantasy, and recreation) (Demetrovics et al., 2011). Questions are responded to on a five-point Likert scale from 1 ("almost never") 
to 5 ("almost always/always") with a minimum score of 4 for each factor (3 for Recreation) and a maximum of 20 for each factor (15 for Recreation).

Additionally, there were questions related to the use of microtransactions in gaming, watching/participating in esports, and gambling on esports. Questions concerning microtransactions (in-game purchases that unlock specific features or give players special abilities, characters, or content) focused on the participants use of microtransactions, the type of microtransaction used (in-game currencies, random chance purchases/loot boxes, in-game advantages, expiration [purchases to continue playing when time-limit]) and the estimated amount of money spent on microtransactions over the past year. Esports questions enquired about participants' engagement in esports, gambling on esports events (if any), and the amount of money spent gambling on esports.

\section{Data analysis}

Descriptive statistics were performed on all 18 questions in relation to gaming included in the survey. Variables included age at which the participant commenced online videogames, hours spent playing online on weekdays/weekends, type of game played, type of device used, and frequency of use and mobile gaming. Based on the IGDS9-SF score, endorsing five or more items out of the nine items in the most severe range (scoring 5 points on each item) indicates gaming disorder. The proposed scoring of scoring of 36 or more out of 45 on the overall scale also indicated disordered gaming (Pontes and Griffiths, 2015). Responses from the MOGQ questionnaire were ranked based on the highest scoring for each of the seven main motives for online gaming.

\section{Results}

\section{Participants}

A total of 166 participants completed the online survey between November 2018 and April 2019. Of these 166 participants, males accounted for 154 participants (92.8\%), females accounted for 10 participants $(6.0 \%)$ and "other" accounted for two participants $(1.2 \%)$. The average age of the population was 30.1 years (S.D. $=8.1$ years). Male participants had an average age of 30.5 years (S.D. $=8.2$ years), female participants had an average age of 24.5 years (S.D. $=4.6$ years) and participants listed as "other" had an average age of 28 years (S.D. $=11.3$ years $)$. In relation to nationality, Irish accounted for $148(89.2 \%)$ of the study population with other nationalities comprising UK (4.8\%) and Lithuanian (1.2\%), with the remaining 4.8\% being Latvian, Polish, Swedish, Portuguese, Hungarian, South African and Croatian. Although country of residence was not enquired about, two participants stated that they have lived in Ireland since childhood.

\section{Gaming behaviours}

The average age at which participants began to play videogames was 14.1 years (S.D. $=6.8$ ). In relation to hours spent online gaming during the weekdays, the full results are listed in Table 2. The most frequent time spent gaming was between 2-5 hours per day on both weekdays and weekends, with $28.0 \%$ participants playing between $2-5$ hours per day on weekdays and $40.2 \%$ participants playing between 2-5 hours per day on weekends. The time periods of 1-2 hours per day and 2-5 hours per day combined accounted for the majority of time spent playing online, with $54.2 \%$ on weekdays and $58.5 \%$ on weekends. A total of $14.5 \%$ stated that they did not play videogames online on weekdays, and $7.8 \%$ stated that they did not play videogames online on weekends. 


\section{Table 1 about here}

\section{Games played online}

Out of 27 games listed, the ten most popular game played online by our participants were Battlefield (27.1\%) followed by PlayerUnknown's Battlegrounds (25.9\%), League of Legends (24.1\%), Grand Theft Auto V (24.1\%), Call of Duty (21.1\%), Overwatch (20.5\%), Fortnite: Battle Royale (19.9\%), Rocket League (16.9\%), Destiny 2 (16.3\%) and Counter-Strike: Global Offensive (13.3\%). The most popular genre of game in the top ten were First-Person Shooter (FPS) games (Battlefield, Call of Duty, Destiny 2, Counter-Strike: Global Offensive, Overwatch) with $50 \%$ of the top ten games within in this genre. The next most common genre in the top ten games listed was Online Multiplayer Battle Royale (PlayerUnknown's Battlegrounds, Fortnite: Battle Royale) followed by Multiplayer Online Battle Arena (League of Legends), action-adventure videogame (GTA V), and vehicular soccer videogame (Rocket League).

\section{Devices used for online gaming}

The most commonly used devices for online gaming were PC gaming and console gaming (e.g., Xbox, PlayStation) with $69.9 \%$ and $69.9 \%$ respectively using these devices to game online. While both these devices had an equal number of participants using them, PC gaming was used on a more frequent basis compared to console gaming. A total of 50.9\% participants engaged in online gaming daily via PC compared to $19.0 \%$ participants engaging in online gaming via console gaming. Only $12.9 \%$ participants using $\mathrm{PC}$ gaming played less than once per week compared to console gaming (44.0\%). A combination of PC and console gaming was used by $42.2 \%$ participants. Only $9.0 \%$ used both devices on a regular basis (greater than $2-4$ times per week).

\section{Mobile gaming}

A total of $43.4 \%$ participants stated that they played mobile games. The most popular game played by our participants was Pokemon Go!, with $43.1 \%$ of participants using mobile gaming, followed by Fortnite (34.7\%), Candy Crush Saga (27.8\%), Clash of Clans (20.8\%), ROBLOX (20.8\%), Toon Blast (19.4\%), Candy Crush Soda Saga (18.1\%), Guns of Glory (18.1\%) and Dragon Bal Z Dokkan (16.7\%). Of all the mobile games surveyed, only three were played every day - Pokemon Go (n=6), Candy Crush Saga $(\mathrm{n}=2)$ and Toon Blast $(\mathrm{n}=1)$. All 72 participants answered the question in relation to their age commencing mobile gaming, with an average age of 20.8 years (S.D. $=8.2$ years)

\section{Microtransactions}

In total, $72.9 \%$ participants stated that they had made microtransactions while gaming. Of the participants that had made microtransactions, $83.6 \%$ had used in-game currencies, $36.2 \%$ had used random chance purchases, $25.9 \%$ had used in-game advantage items, and $16.3 \%$ had used expiration microtransactions. Over half $(53.7 \%)$ made only one type of microtransaction, $26.4 \%$ had made two types of microtransaction, $15.7 \%$ had made three different types of microtransaction, and no participants had made all four types of microtransactions. Five participants declined to answer (4.1\%). The most common combination of microtransactions used were in-game currencies and random chance purchases $(17.4 \%)$. Of the money spent on microtransactions, the most frequent amount spent was $€ 1-€ 20$ per year $(26.5 \%)$, followed by $€ 20-€ 50$ (23.1\%), €50-€100 (22.3\%), €100-€200 (8.3\%), €200-€500 (6.6\%), €500-€1000 $(4.1 \%)$ and $>€ 1000(0.8 \%)$.

Tables 2 and 3 about here 


\section{Motives for online gaming}

Each motivation was ranked based on the total score from each of the questions related to one of the seven motives for online gaming. Each question was scored between one and five based on the Likert scale ranging from "almost never" to "almost always/always". The main motivation for online gaming was recreation $(13.3$, S.D. $=2.7)$. This was followed by coping $(11.1$, S.D. $=4.1)$, competition $(10.9$, S.D. $=4.6)$, skill development $(10.3$, S.D. $=4.9)$, social (9.6, S.D. $=4.6)$, escape $(9.2$, S.D. $=5)$, and fantasy (7.7, S.D. $=4.3)$. The main motivations for online gaming for non-disordered gamers $(94.6 \%)$ were recreation $(13.3$, S.D. $=2.8)$, coping $(10.9$, S.D. $=4.0)$, competition $(10.5$, S.D. $=4.5)$, skill development (10.2, S.D. $=4.9)$, social $(9.4$, S.D. $=4.5)$, escape $(8.8$, S.D. $=4.8)$, and fantasy $(7.5$, S.D. $=4.2)$. The main motivations for online gaming for disordered gamers (5.4\%) were competition (16.3, S.D. $=$ 3.7), escape $(16.2$, S.D. $=4.3)$, coping $(15.1$, S.D. $=3.7)$, recreation $(13.8$, S.D. $=2.0)$, social $(13.7$, S.D. $=3.5)$, skill development $(12.7$, S.D. $=3.2)$, and fantasy $(11.6$, S.D. $=4.7)$.

\section{Table 4 about here}

\section{Esport gaming}

Half of the total participants $(50 \%)$ stated that they had participated in or watched esports. However, only $11.4 \%$ stated that they had gambled on an esport event. Of the 19 participants that engaged in gambling on esports events, 17 participants $(89.5 \%)$ gambled less than once per month on esports, with one participant gambling once per month, and one participant gambling 2-3 times per month. In relation to the amount of money spent gambling on esports in the past year, eight participants spent between $€ 1-€ 20$ per year, five spent between $€ 20-€ 50$, $2(10.5 \%)$ spent between $€ 50-€ 100$, one $(5.3 \%)$ spent between $€ 100-€ 200$ and one $(5.3 \%)$ spent between $€ 200-€ 500$. (Two participants declined to answer how much they had spent on esports).

\section{Disordered gamers}

Based on the criteria listed for disordered gaming (see Methods), four participants (2.4\%) met the IGDS9-SF criteria for disordered gaming. By using the proposed scale cut-off of 36 points or greater meant that nine participants $(5.4 \%)$ were classified as having gaming disorder. However it must be reiterated that this is a suggested cut-off point for diagnosis of gaming disorder is for research purposes only, and that the current IGDS-SF9 criteria are used worldwide. Of the nine participants identified as disordered gamers and gamers with high IGDS-SF9 scores, eight were male. A total of $12.7 \%$ participants had scores between 27-36, $48.8 \%$ had scores between $18-27$, and $33.1 \%$ had scores between 9-18 (the lowest score achievable on the scale is 9 ). The average age by disordered gamers commencing the playing of videogames was 12 years (S.D. $=5.4$ years). Hours spent gaming on weekdays were 2-5 hours per day $(n=4), 1-2$ hours per day $(n=2), 5-8$ hours per day $(n=2)$ and $>12$ hours per day $(\mathrm{n}=1)$. The hours spent gaming at the weekend were most frequently 8-12 hours per day $(\mathrm{n}=3)$ and $>12$ hours per day $(n=3)$, followed by $30-60$ mins per day $(n=1), 2-5$ hours per day $(n=1)$, and 5-8 hours per day $(n=1)$. PCs was the most used device for online gaming, with eight disordered gamers using PCs either most days (4-6 times a week) or every day. In comparison, two disordered gamers stated they use consoles to the same frequency. The most commonly made microtransactions in the disordered gamer group were in-game currencies $(n=7)$, random chance purchases $(n=3)$, in-game advantage items $(n=2)$ and expiration $(n=2)$. The most frequent amount of money spent on microtransactions was $€ 200-€ 500(n=4)$ followed by $€ 20$ $€ 50(\mathrm{n}=2), € 50-€ 100(\mathrm{n}=2)$ and $€ 1-€ 20(\mathrm{n}=1)$. Eight disordered gamers watched and/or participated in esports but only four of them had gambled on esports, all with a frequency of less than once per month. 


\section{Discussion}

The aim of this study is to examine the gaming characteristics of individuals engaging in online gaming in Ireland and to ascertain whether features of gaming disorder are present in this population. The majority of the participants were male (92.8\%), which is consistent with males using videogames more regularly than females (Mentzoni et al., 2011). The percentage of male respondents in this survey was only slightly higher than other studies utilising an online recruitment strategy, with males accounting for $77 \%$ (Hussain et al., 2012) and $85 \%$ (Pontes et al., 2014) of the researched population. The average age of the participants surveyed was 30.1 years (S.D. $=8.1$ ), in line with other studies investigating adult populations in gaming disorder (Griffiths et al., 2004b).

This survey identified four participants as endorsing the IGDS9-SF criteria for gaming disorder (2.4\%). The worldwide prevalence of gaming disorder is estimated at being up to $4.7 \%$ (Feng et al., 2017) and the present study looked at two different cut-off points using the same scale to meet criteria for gaming disorder. Four participants $(2.4 \%)$ met the standard cut-off point of endorsing five or more out of nine items in the most severe range on the IGDS9-SF and nine participants scored greater than 36 out of 45 on the IGDS9-SF scale $(5.4 \%)$. Based on this study, the prevalence of gaming disorder among regular gamers using IGDS9-SF criteria in Ireland is $2.4 \%$. Using research-based cut-off criteria (scoring 36 or more out of 45 ), the prevalence rate increased to $5.4 \%$ of participants with possible gaming disorder.

The average age in which participants began online gaming was 14.1 years old and the average age in which our disordered gamers began to engage in online gaming was 12 years old. This appears to confirm previous studies which note that younger age of onset in online gaming has been associated with an increased risk of developing gaming disorder (Lopez-Fernandez et al., 2014) as well as years spent online gaming (Gentile, 2009).

The average time spent gaming during the weekdays and the weekends was 2-5 hours per day, with the majority of participants engaging between 1-5 hours per day on both weekdays and weekends. This is in line with other studies documenting average gaming time at 2.49 hours per day (Grüsser et al., 2006) and 25 hours per week (Griffiths et al., 2004a). Disordered levels of gameplay has been difficult to quantify as it has been previously shown that even playing over 80 hours per week can occur without necessarily meeting gaming disorder criteria (Griffiths, 2010). However, hours spent online gaming has been shown in multiple studies to be a risk factor for developing gaming disorder (Mihara and Higuchi, 2017) and individuals with gaming disorder have been shown to spend more time gaming online than their nondisordered counterparts (Gentile, 2009). Among the disordered gaming cohort in the present study, the most frequent time spent gaming during the weekdays was 2-5 hours per day $(n=4)$ and the shortest time played during the weekdays in this group was 1-2 hours per day $(n=2)$. In contrast, $21.7 \%$ of participants in the non-disordered group played for shorter periods of time $(<1$ hour per day) compared to none of the disordered gaming group during the weekdays. Increased hours of gameplay during weekdays was listed as a risk factor for the development of gaming disorder (Mihara and Higuchi, 2017) and this was seen in this study's disordered gaming group. Weekend play among the disordered gaming group was higher compared to the non-disordered gaming group, with six participants (67\%) gaming over eight hours per day on the weekends, compared to 16 participants in the non-disordered gaming group (10\%). As mentioned previously, increased frequency of gaming is a risk factor for developing gaming disorder (Mihara and Higuchi, 2017) and this is seen in weekend play among the disordered gamers. 
First person shooter (FPS) games were the most frequently played game among participants with this genre comprising 50\% of the top ten games played. FPS and Action-Adventure games (also included in the top ten games in this survey) have been associated with increased risk of problematic videogame use (Elliott et al., 2012). MOBA games, also included in the top ten games in this study, have also shown a relationship between increased impulsivity and problematic use of these types of game (Nuyens et al., 2016). PC gaming was the platform most frequently used for regular online gaming in our survey, consistent with previous studies in this area (Király et al., 2017).

Mobile gaming was utilised by only $43.4 \%$ of participants and only nine participants $(5.4 \%)$ had used mobile gaming on a daily basis. The most common game played was Pokemon Go! which has been shown to be used as a maladaptive coping strategy in a small number of individuals by using the augmented reality provided by the game to escape their own reality (Das et al., 2017). However, given the relative infrequency of the use of mobile gaming, mobile gaming addiction was not a major issue for this study group. This finding this concurs with previous cross-cultural research showing that gaming addiction among mobile users does not appear to be problematic (Lopez-Fernandez et al., 2018).

Making in-game microtransactions was common among the participants (72.9\%). In-game currencies were the most common microtransactions made (83.6\%) and in-game currency combined with random chance purchases $(17.4 \%)$ was the most commonly used combination. In-game currencies have been shown to increase spending by using a different medium instead of traditional money (Duverge, 2016) and can encourage players to spend money to purchase currency ("pay-to-skip") instead of the hours of gameplay required to achieve the same amount of in-game currency ("grinding") (Columb et al., 2019). Random chance purchases or "loot boxes' have also shown characteristics akin to slot machine gambling and have been described as "virtual games of chance" (Griffiths, 2018). The potential addictive properties and frequent use in this group could increase risk of addictive use and monetary spending as a result. However, in this study, the majority of participants $(71.9 \%)$ making microtransactions spent less than $€ 100$ a year on microtransactions. Among the disordered gamers, the most common (and largest) amount spent on microtransactions was $€ 200-€ 500 \quad(n=4)$ compared to six participants in the non-disordered gaming group spending more than $€ 500$ per year. Based on the findings, the present study did not show any relationship between money spent on microtransactions and disordered gaming. Given that some disordered gamers can spend too much money on microtransactions and/or 'chase losses' by making microtransaction payments to improve gameplay performance (King and Delfabbro, 2018), future Irish studies including larger numbers of disordered gamers may show increased spend compared to their nondisordered counterparts.

Esports participation and/or viewing was also assessed, given its rise in popularity in recent times. There has been research to show a large gambling element associated with esports (Bányai et al., 2019) and gambling on esports is estimated to reach $\$ 10$ billion (US) by 2020 (Griffiths, 2017). In the present study, only $11.4 \%$ of the participants watching esports gambled on esports, and the majority of these participants gambled less than once per month on esports (89.5\%). This implies that esport watching and betting on esports were not concerns for the participants in this study.

Of the seven main motives for online gaming, recreation was the most common motive seen among non-disordered gamers and concurs with previous studies in relation to non-disordered gamers (Kim et al., 2016). Among disordered gamers, the most common motive for online gaming was competition, followed by escape and coping. These motives were also the top three motives listed by disordered gamers in other studies (Kim et al., 2016). Using gaming as a 
means of coping and escape can ease psychiatric distress and lead to the development and the continuation of the problem behaviour (Király et al., 2015). The use of gaming as a means of modifying psychiatric distress rather than using gaming as a pleasurable pursuit may be an important factor in screening individuals for possible gaming disorder in the future.

There are some limitations to this study. The main limitation is the relatively small total number of disordered gamers identified by this study (and the small sample size more generally). This likely reflects that online gamers in Ireland are using global forums such as Reddit, and that individuals using forums would be regular online gamers compared to the casual online gaming player. Country of current residence was not enquired about in the present study. Despite the fact that participants were solely recruited through Irish gaming forums and communities, this may not mean that the participants were necessarily currently living in Ireland. Given the low overall total number of disordered gamers, it is difficult to make any statistical comparisons between disordered and non-disordered gamers. Further large population-based studies are required to achieve a more accurate measure of the prevalence and behaviours of gaming disordered individuals in an Irish population. This study also used self-report measures to identify gaming disorder as opposed to a clinician-based diagnosis, which may lead to greater inaccuracy in the identification of gaming disordered individuals. Finally, the participants in this study were self-selecting, leading to possible selection bias in this population.

Given the increasing popularity of online gaming and likely future increase in presentations of problematic gaming, clinicians should be aware of practical steps and advice concerning managing problematic gaming and gaming disorder. For most individuals, engaging in online gaming is a harmless pastime and can have positive prosocial and educational benefits (Columb et al., 2019). When addressing possible gaming disorder, ensuring that gaming is used as a social event (rather than playing solo) and that the gamer has other pursuits and hobbies outside of gaming can be important (Griffiths and Meredith, 2009). Online support forums concerned with excessive and problematic gaming can offer practical advice and experiential accounts for gamers (Griffiths and Meredith, 2009). Cognitive behavioural therapy offers the most promising avenue of treatment for gaming disorder, with the aim of increasing prosocial skills and the use of real life activities to reduce the amount of time spent gaming (Griffiths and Meredith, 2009)

In conclusion, this is the first ever study examining gaming disorder and gaming characteristics in Ireland. The results of this study show that gamers in Ireland display many of the characteristics of gaming and gaming disorder globally. The prevalence of disordered gaming in this population from this study highlights the need for increased screening for gaming disorder. At-risk individuals may be displaying some of the risk factors and characteristics listed in this study, including gaming as a means of coping or escape. Finally, further studies are required to ascertain the extent of gaming disorder in Ireland with an emphasis on early detection of these individuals and providing pathways for further treatment of this cohort.

\section{Financial Support}

This research received no specific grant from any funding agency, commercial or not-for-profit sectors.

\section{Conflicts of Interest}


David Columb has no conflicts of interest to disclose. Mark D. Griffiths has no conflicts of interests to disclose. Colin O'Gara has no conflicts of interests to disclose.

\section{Ethical Standards}

The authors assert that all procedures contributing to this work comply with the ethical standards of the relevant national and institutional committee on human experimentation with the Helsinki Declaration of 1975, as revised in 2008. The study protocol was approved by the ethics committee of University College Dublin.

\section{References}

American Psychiatric Association (2013). Diagnostic and statistical manual of mental disorders, (5th ed.). Arlington, VA: American Psychiatric Association.

Bányai F, Griffiths MD, Király O, Demetrovics Z (2019). The psychology of esports: A systematic literature review. Journal of Gambling Studies, 35, 351-365.

Chalk A (2018). Fortnite passes PUBG with 3.4 million concurrent players. Retrieved from https://www.pcgamer.com/fortnite-passes-pubg-with-34-million-concurrent-players/

Cocking S (2018). Will 2018 be the year that Ireland finally embraces eSports? Retrieved from https://irishtechnews.ie/will-2018-be-the-year-that-ireland-finally-embraces-esports/

Columb D, Griffiths M, O'Gara C (2019). Online gaming and gaming disorder: more than just a trivial pursuit. Irish Journal of Psychological Medicine, 1-7. Retrived from doi:10.1017/ipm.2019.31

Das P, Zhu MO, Mclaughlin L, Bilgrami Z, Milanaik R (2017). Augmented reality video games: new possibilities and implications for children and adolescents. Multimodal Technologies and Interaction, $\mathbf{1}, 8$.

Demetrovics Z, Urbán R, Nagygyörgy K, Farkas J, Zilahy D, Mervó B, Reindl A, Ágoston C, Kertész A, Harmath E (2011). Why do you play? The development of the motives for online gaming questionnaire (MOGQ). Behavior Research Methods, 43, 814-825.

Duverge G (2016). Insert more coins: The psychology behind microtransactions. Retrieved from https://www.tuw.edu/content/psychology/psychology-behind-microtransactions/

Elliott L, Golub A, Ream G, Dunlap E (2012). Video game genre as a predictor of problem use. Cyberpsychology, Behavior, and Social Networking, 15, 155-161.

Feng W, Ramo D, Chan S, Bourgeois J (2017). Internet gaming disorder: trends in prevalence 1998-2016. Addictive Behaviors, 75, 17.

Gamesindustry International (2004). Blizzard Entertainment announces World Of Warcraft "street date". Retrieved from https://www.gamesindustry.biz/articles/blizzardentertainment-announces-world-of-warcraft-street-date-november-23-2004

Gentile D (2009). Pathological video-game use among youth ages 8 to 18: A national study. Psychological Science, 20, 594-602.

Griffiths MD (2010). The role of context in online gaming excess and addiction: Some case study evidence. International Journal of Mental Health and Addiction, 8, 119-125.

Griffiths MD (2017). The psychosocial impact of professional gambling, professional video gaming \& eSports. Casino \& Gaming International, 28, 59-63.

Griffiths MD (2018). Is the buying of loot boxes in video games a form of gambling or gaming? Gaming Law Review, 22, 52-54.

Griffiths MD, Davies MN, Chappell D (2004a). Demographic factors and playing variables in online computer gaming. Cyberpsychology, Behavior, and Social Networking, 7, 479-487. 
Griffiths MD, Davies MN, Chappell D (2004b). Online computer gaming: a comparison of adolescent and adult gamers. Journal of Adolescence, 27, 87-96.

Griffiths MD, Meredith A (2009). Videogame addiction and its treatment. Journal of Contemporary Psychotherapy, 39, 247-253.

Grüsser SM, Thalemann R, Griffiths MD (2006). Excessive computer game playing: evidence for addiction and aggression? Cyberpsychology, Behavior, and Social Networking, 10, 290-292.

Hamari J, Sjöblom M (2017). What is eSports and why do people watch it? Internet Research, 27, 211-232.

Hussain Z, Griffiths MD, Baguley T (2012). Online gaming addiction: Classification, prediction and associated risk factors. Addiction Research \& Theory, 20, 359-371.

Kelleher L (2019). Irish teenagers being treated for gaming addiction as psychiatrists warn disorder is becoming more common. Retrieved from https://www.irishmirror.ie/news/irish-news/irish-teenagers-being-treated-gaming14009893

Kim NR, Hwang SS-H, Choi J-S, Kim D-J, Demetrovics Z, Király O, Nagygyörgy K, Griffiths MD, Hyun SY, Youn HC (2016). Characteristics and psychiatric symptoms of Internet gaming disorder among adults using self-reported DSM-5 criteria. Psychiatry Investigation, 13, 58.

King DL, Delfabbro PH (2018). The concept of "harm" in Internet gaming disorder. Journal of Behavioral Addictions, 7, 562-564.

Király O, Sleczka P, Pontes HM, Urbán R, Griffiths MD, Demetrovics Z (2017). Validation of the ten-item Internet Gaming Disorder Test (IGDT-10) and evaluation of the nine DSM-5 Internet Gaming Disorder criteria. Addictive Behaviors,, 64, 253-260.

Király O, Urbán R, Griffiths MD, Ágoston C, Nagygyörgy K, Kökönyei G, Demetrovics $\mathbf{Z}$ (2015). The mediating effect of gaming motivation between psychiatric symptoms and problematic online gaming: An online survey. Journal of Medical Internet Research, 17, e88.

Lanier L (2019). Video games could be a $\$ 300$ billion industry by 2025. Variety.com. Retrieved from https://variety.com/2019/gaming/news/video-games-300-billionindustry-2025-report-1203202672/

Lopez-Fernandez O, Honrubia-Serrano ML, Baguley T, Griffiths MD (2014). Pathological video game playing in Spanish and British adolescents: Towards the exploration of Internet Gaming Disorder symptomatology. Computers in Human Behavior, 41, 304-312.

Lopez-Fernandez O, Männikkö N, Kääriäinen M, Griffiths MD, Kuss DJ (2018). Mobile gaming and problematic smartphone use: A comparative study between Belgium and Finland. Journal of Behavioral Addictions, 7, 88-99.

Mamun MA, Griffiths MD (2019). The psychosocial impact of extreme gaming on Indian PUGB gamers: The case of PUGB (PlayerUnknown's Battlegrounds). International Journal of Mental Health and Addiction, 1-5. Retrived from https://doi.org/10.1007/s11469-019-00102-4

Meng J, Williams D, Shen C (2015). Channels matter: Multimodal connectedness, types of co-players and social capital for Multiplayer Online Battle Arena gamers. Computers in Human Behavior, 52, 190-199.

Mentzoni RA, Brunborg GS, Molde H, Myrseth H, Skouverøe KJM, Hetland J, Pallesen S (2011). Problematic video game use: estimated prevalence and associations with mental and physical health. Cyberpsychology, Behavior, and Social Networking, 14, 591-596. 
Mihara S, Higuchi S (2017). Cross- sectional and longitudinal epidemiological studies of I nternet gaming disorder: A systematic review of the literature. Psychiatry and Clinical Neurosciences, 71, 425-444.

Nuyens F, Deleuze J, Maurage P, Griffiths MD, Kuss DJ, Billieux J (2016). Impulsivity in multiplayer online battle arena gamers: Preliminary results on experimental and selfreport measures. Journal of Behavioural Addictions, 5, 351-356.

O'Brien C (2019). Esports growth sees 22\% of adults watching or participating - survey. Retrieved from https://www.irishtimes.com/business/technology/esports-growth-sees22-of-adults-watching-or-participating-survey-1.4055320

Pollak S, Gallagher C (2019). Fortnite World Cup: Irish teenager wins $\$ 50,000$ prize. The Irish Times. Retrieved from https://www.irishtimes.com/business/technology/fortniteworld-cup-irish-teenager-wins-50-000-prize-1.3969972

Pontes HM, Griffiths MD (2015). Measuring DSM-5 Internet gaming disorder: Development and validation of a short psychometric scale. Computers in Human Behavior, 45, 137143.

Pontes HM, Kiraly O, Demetrovics Z, Griffiths MD (2014). The conceptualisation and measurement of DSM-5 Internet Gaming Disorder: The development of the IGD-20 Test. PloS One, 9, e110137.

Wepc (2019). 2019 video game industry statistics, trends \& data. Retrieved from https://www.wepc.com/news/video-game-statistics/

World Health Organization (2018). International statistical classification of diseases and related health problems (11th Revision) - 6C51 Gaming Disorder. Retrieved from https://icd.who.int/browse11/1-m/en\#/http://id.who.int/icd/entity/1448597234 
Table 1: Hours spent online gaming

\begin{tabular}{lcclcc}
\hline Weekdays & $n$ & $\%$ & Weekends & $n$ & $\%$ \\
\hline No play during weekdays & 24 & 14.5 & No play during weekends & 13 & 7.8 \\
$<15$ mins & 5 & 3.0 & $<15$ mins & 0 & 0.0 \\
15-30mins & 5 & 3.0 & $15-30$ mins & 2 & 1.2 \\
30-60mins & 24 & 14.5 & 30-60mins & 8 & 4.8 \\
1-2 hours per day & 44 & 26.5 & $1-2$ hours per day & 31 & 18.7 \\
2-5 hours per day & 46 & 27.7 & 2-5 hours per day & 66 & 39.8 \\
5-8 hours per day & 14 & 8.4 & 5-8 hours per day & 24 & 14.5 \\
8-12 hours per day & 2 & 1.2 & $8-12$ hours per day & 17 & 10.2 \\
$>12$ hours per day & 2 & 1.2 & >12 hours per day & 5 & 3.0 \\
Total & 166 & 100 & Total & 166 & 100 \\
& & & & & \\
\hline
\end{tabular}


Table 2. Microtransactions used by Irish gamers

\begin{tabular}{|c|c|c|}
\hline & $n$ & $\begin{array}{c}\% \\
\text { (based on total } n \\
\text { using } \\
\text { microtransactions) }\end{array}$ \\
\hline \multicolumn{3}{|l|}{1 Microtransaction } \\
\hline Expiration & 6 & 5.0 \\
\hline In-game currency & 49 & 40.5 \\
\hline Random chance purchases & 4 & 3.3 \\
\hline In-game advantage items & 6 & 5.0 \\
\hline Total & 65 & 53.7 \\
\hline \multicolumn{3}{|l|}{2 Microtransactions } \\
\hline$\overline{\text { Expiration + In-game currency }}$ & 3 & 2.5 \\
\hline Expiration + Random chance purchases & 1 & 0.8 \\
\hline Expiration + In-game advantage items & 0 & 0.0 \\
\hline In-game currency + Random chance purchases & 21 & 17.4 \\
\hline In-game currency + In-game advantage items & 5 & 4.1 \\
\hline Random chance purchases + In-game advantage items & 2 & 1.7 \\
\hline Total & 32 & 26.4 \\
\hline \multicolumn{3}{|l|}{3 Microtransactions } \\
\hline 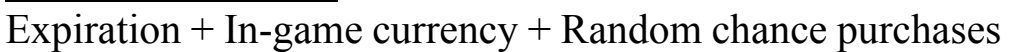 & 4 & 3.3 \\
\hline Expiration + In-game currency + In-game advantage items & 5 & 4.1 \\
\hline $\begin{array}{l}\text { In-game currency }+ \text { Random chance purchases }+ \text { In-game } \\
\text { advantage items }\end{array}$ & 10 & 8.3 \\
\hline Total & 19 & 15.7 \\
\hline \multicolumn{3}{|l|}{4 Microtransactions } \\
\hline $\begin{array}{l}\text { Expiration + In-game currency + Random chance purchases } \\
+ \text { In-game advantage items }\end{array}$ & 0 & 0 \\
\hline Total & 0 & \\
\hline Declined to answer & 5 & 4.1 \\
\hline Overall Total & 121 & 100 \\
\hline
\end{tabular}


Table 3: Money spent on microtransactions during gaming

\begin{tabular}{lcc}
\hline & $n$ & $\begin{array}{c}\% \\
\text { (Based on total number } \\
\text { using microtransactions) }\end{array}$ \\
\hline I haven't spent money & 10 & 8.3 \\
$€ 1-20$ & 32 & 26.5 \\
$€ 20-50$ & 28 & 23.1 \\
$€ 50-100$ & 27 & 22.3 \\
$€ 100-200$ & 10 & 8.3 \\
$€ 200-500$ & 8 & 6.6 \\
$€ 500-1000$ & 5 & 4.1 \\
$>€ 1000$ & 1 & 0.8 \\
Total & 121 & 100 \\
& & \\
\hline
\end{tabular}


Table 4: Motives for online gaming

\begin{tabular}{|c|c|c|}
\hline & $\begin{array}{c}\text { Average } \\
\text { Score }\end{array}$ & S.D. \\
\hline \multicolumn{3}{|l|}{ Total $(n=166)$} \\
\hline Recreation & 13.3 & 2.7 \\
\hline Coping & 11.1 & 4.1 \\
\hline Competition & 10.9 & 4.6 \\
\hline Skill Development & 10.3 & 4.9 \\
\hline Social & 9.6 & 4.6 \\
\hline Escape & 9.2 & 5 \\
\hline Fantasy & 7.7 & 4.3 \\
\hline \multicolumn{3}{|c|}{ Non-disordered gamers $(n=157)$} \\
\hline Recreation & 13.3 & 2.8 \\
\hline Coping & 10.9 & 4.0 \\
\hline Competition & 10.5 & 4.5 \\
\hline Skill Development & 10.2 & 4.9 \\
\hline Social & 9.4 & 4.5 \\
\hline Escape & 8.8 & 4.8 \\
\hline Fantasy & 7.5 & 4.2 \\
\hline \multicolumn{3}{|c|}{ Disordered gamers $(\mathrm{n}=9)$} \\
\hline Competition & 16.3 & 3.7 \\
\hline Escape & 16.2 & 4.3 \\
\hline Coping & 15.1 & 3.7 \\
\hline Recreation & 13.8 & 2.0 \\
\hline Social & 13.7 & 3.5 \\
\hline Skill Development & 12.7 & 3.2 \\
\hline Fantasy & 11.6 & 4.7 \\
\hline
\end{tabular}

